\title{
TECNOCIENCIA, IRONÍA Y CUIDADO
}

\author{
Eduardo A. Rueda Barrera \\ Presidente de la Red Latinoamericana de \\ Educación en Bioética REDLACEB
}

\begin{abstract}
Resumen: Este trabajo se desarrolla en tres partes. En la primera defiendo la pertinencia de la expresión tecnociencia. Justifico la pertinencia del término tanto en a) la evidencia empírica que arrojan los estudios científico-sociales en ciencia y tecnología, como en b) la redescripción filosófica que sobre la relación entre ciencia y técnica ofrece Heidegger. En la segunda, pongo de manifiesto la ironía que emerge al considerar la tecnociencia como «factor de modernidad». Esta ironía surge, de acuerdo con Gianni Vattimo, de «la transformación del mundo en un lugar donde ya no hay hechos sino interpretaciones». De esta circunstancia se desprende la transformación del potencial de dominación de la tecnociencia, que ha ocupado el trabajo crítico de los frankfurtianos, en el ideal normativo de reducción de la violencia. En la última parte muestro cómo debe comprenderse este ideal: el ideal de reducción de la violencia ha de entenderse como cuidado. Siguiendo a Agnes Heller, explico cómo el cuidado, para ser real, implica un doble deber moral: responsabilidad ante los otros y resurrección de la naturaleza. Insisto en que tanto la responsabilidad ante los otros como la resurrección de la naturaleza solo pueden resultar genuinas si los Otros y lo Otro (la naturaleza) constituyen no una exterioridad, sino una parte de lo que somos.
\end{abstract}

Palabras clave: tecnociencia, ironía, cuidado, ideal de no violencia, responsabilidad por los otros, resurrección de la naturaleza. 


\title{
Technoscience, irony and care
}

\begin{abstract}
This paper has three sections. Firstly, I explore what the term technoscience does mean. I justify the relevance of the term on both a) the empirical evidence that social studies of science bring up, and b) the philosophical redescription that Heidegger offers on the relationship between science and technique. Secondly, I show up the irony that emerge when we consider technoscience as [the] «factor of modernity». This irony arises, according to Gianni Vattimo, from «the transformation of the world in a place in where there are not facts anymore but interpretations. From this circumstance follows the transformation of the potential for domination of technoscience, which has occupied the critical work of the Frankfurters, into the normative ideal of reducing violence. Finally, I show how this ideal should be understood: the ideal of reducing violence must be understood as care. Following Agnes Heller, I explain how care, to be real, implies a double moral duty: responsibility before others and resurrection of nature. I insist that both the responsibility to others and the resurrection of nature can only be genuine if the Others and the Other (nature) constitute not an exteriority, but a part of who we are.
\end{abstract}

Keywords: technoscience, irony, care, ideal of no violence, responsibility for the others, resurrection of nature.

\section{Eduardo A. Rueda Barrera}

Ph.D. en Filosofía de la Universidad del País Vasco (Grado de Honor Summa Cum Laude y «Doctor Europeus») y Médico cirujano de la Pontificia Universidad Javeriana. Co-coordinador del Grupo de Trabajo en Filosofía Política del Consejo Latinoamericano de Ciencias Sociales (CLACSO). Investigador Senior de Colciencias. Presidente de la Red Latinoamericana y del Caribe de Educación en Bioética (REDLACEB). Director ejecutivo y miembro fundador de la Red de Formación ética y ciudadana en Colombia. Miembro fundador de la Red Internacional de Bioderecho y miembro del Consejo Directivo de la Red Latinoamericana y del Caribe de Bioética de UNESCO. Exdirector y Profesor Titular del Instituto de Bioética de la Universidad Javeriana (2013-2019). Coordinador del Observatorio de Derechos de la naturaleza - Nodo Colombia.

Correo electrónico: eruedab@gmail.com 
«Pero donde hay peligro, crece también lo salvador» Hölderlein

De la cita que hago de Hölderlein se infiere el argumento básico que me propongo desarrollar: el de que la tecnociencia porta no solo un equipaje de peligro, de riesgos frecuentemente incalculables (pienso en las consecuencias potenciales de la guerra nuclear o de la manipulación genética, y en los efectos sobre el clima y la capa de ozono ocasionados por la actividad tecnoindustrial, entre otros), sino que, irónicamente, ella lleva consigo un potencial salvador, por así decirlo, que por lo pronto quisiera expresar, a la manera de Vattimo, bajo la forma de un ideal normativo, el ideal de reducción de la violencia.

\section{1. ¿Y por qué tecnociencia?}

a) Es ciertamente en el campo de los estudios científicosociales en donde se ha cuestionado más enfáticamente la frontera entre ciencia y tecnología. «De hecho, los estudios culturales analizan la intersección de cultura, ciencia y tecnología, tratándolas no como entidades independientes, sino como entramados», dice Escobar (1999: 336). Desde este punto de vista, cultura, ciencia y tecnología se articulan en función de modos específicos de producción cultural las llamadas tecnoculturas - y de producción científica y tecnológica - la llamada tecnociencia-, siendo que ya ninguna de ellas puede ser producida o comprendida sin involucrar la otra.

b) Es Heidegger el filósofo que más claramente expone la relación indisoluble que existe entre ciencia y técnica, y el modo en que la primera se subordina a la segunda. Es en la explicación que nos ofrece de la ciencia como empresa en donde esta imbricación aparece con mayor nitidez. Al poner de manifiesto a la ciencia como una empresa sujeta a resultados previos, referidos al «proyecto de un sector de objetos», Heidegger da cuenta de la necesidad que ella 
tiene de institucionalizarse. Su institucionalización proviene «nada menos que del aseguramiento de la primacía del método por encima de lo ente» (Heidegger 1998: 70), es decir, de la prioridad del método por encima de la naturaleza-objeto y de la historia-objeto. El método «se convierte [así] en algo objetivo dentro de la investigación», de tal manera que «el investigador se ve espontánea y necesariamente empujado dentro de la esfera de lo técnico en sentido esencial» (1998: 70). El científico es, de acuerdo con esta perspectiva, un técnico en sentido propio. De hecho, Heidegger se opone a la idea muy extendida según la cual la técnica moderna solo pudo progresar una vez logró apoyarse en la ciencia exacta de la naturaleza. «Pero, podría objetarse que la ciencia matemática ha surgido casi dos siglos antes que la técnica moderna. ¿Cómo podría entonces estar ya al servicio de la técnica moderna? Los hechos atestiguan lo contrario. ¿No progresó la técnica moderna cuando pudo apoyarse en la ciencia exacta de la naturaleza? Historiográficamente calculada la objeción es correcta. Históricamente pensada, no encuentra lo verdadero», escribe Heidegger (1993: 91). Según él, es la esencia de la técnica, que él establece como «el imperar de lo dispuesto, que exige el establecimiento de la naturaleza como constante» (1993: 92), lo que hace posible el ámbito de representación de la física moderna. En efecto, lo constante es un imperativo necesario para la empresa de las ciencias naturales: corresponde a la estabilidad del mundo en una imagen. Sin duda, ninguna ciencia natural moderna se habría desarrollado sin la imagen estabilizada, ese recurso fundamental del mirar y del hablar. Sin duda, ella no habría crecido jamás en el espacio de un universo heraclitiano, cambiante, proteico, no fijable en imágenes. Pero, también sin duda, como Heidegger enseñó, el imperativo de la imagen estable no procede de la ciencia (antigua o medieval) sino de la técnica. Esta es la segunda razón por la cual prefiero hablar de tecnociencia. Hablar así nos remite inmediatamente al carácter esencialmente técnico que distingue la empresa de la ciencia en la modernidad.

\section{Tecnociencia e ironía}

De acuerdo con lo que anunciara al inicio de este trabajo, me referiré a una situación que he tildado, con Rorty, de irónica. Por ironía entiendo, de la mano de este autor, aquello que se opone al sentido común (Rorty 1991: 92). En otras palabras, entiendo por ella la experiencia que resulta de evaluar una situación como opuesta a la que se esperaría resultara de acuerdo con 
el régimen de expectativas que define nuestro sentido común. Pues bien, el sentido común, después del trabajo crítico de la Escuela de Frankfurt, señalaba a la racionalidad técnica como la racionalidad de la dominación. Pues según los frankfurtianos la racionalidad técnica conduce a la integración de los individuos en el statu quo a través de las industrias culturales y, entonces, a su masificación: a la alienación de su capacidad crítica y a la disolución de las huellas de una experiencia auténtica. La ironía surge cuando nos damos cuenta que de la tecnociencia pueden esperarse también cosas opuestas: transformación de las estructuras de modernidad dominante, proliferación de alteridades, heterotopías, resurrección estética de la naturaleza dominada, en fin, «subversiones».

Analizaré esta ironía en dos momentos: uno primero, en el que quisiera ubicar el papel de la tecnociencia como factor de transformación del mundo moderno para entender lo que ella misma parece llevar de salvador. Y uno segundo, en el que quisiera mostrar las posibilidades contrahegemónicas de las tecnologías digitales y moleculares emergentes.

\subsection{Tecnociencia, nihilismo, reducción de la violencia}

Es a la tecnociencia, escribe Gianni Vattimo, a la que debemos la multiplicación del mundo en imágenes contradictorias «que luchan entre sí». Aunque es ella la que consagra el mundo como un hecho, es decir la que lo fabrica como un mundo de objetos, al congelar el devenir de lo ente en imágenes constantes, es también la que, paradójicamente, y por proceder de esta manera, instaura una relación con las cosas específicamente moderna, una relación que se despliega como una progresiva confrontación de visiones del mundo. De acuerdo con esta descripción, la tecnociencia, consagrada por el sentido común como la empresa del conocimiento de la 'realidad' y del descubrimiento de nuevas posibilidades de hacer uso de ella, ha terminado disolviendo «todo principio de realidad» (Vattimo 1995: 65-67). Pensemos, por ejemplo, en el efecto disolvente que los desarrollos tecnocientíficos de la época moderna han tenido sobre hechos como los siguientes: que madre solo hay una; que lo natural es todo aquello que se opone a lo artificial, al diseño; que la materia es continuidad palpable; que lo local es aquí. En efecto, los hijos podrían tener, en un futuro ya al alcance, hasta tres madres; la biología se ha vuelto diseñable; la materia es una probabilidad cuántica; lo local es aquí y allá — como cuando vemos un partido de fútbol por televisión- o aquí y en cualquier parte - como sucede cuando se encuentran apenas virtualmente los amantes. En esta hora, en verdad, del mundo ya no quedan «hechos», sino interpretaciones diversas, en lucha, ancladas a lugares específicos desde donde son elaboradas. A esto llamaremos, inspirados en Nietzsche: nihilismo. 
Esta afirmación última, que constituye, según Vattimo, la verdad básica de la hermenéutica - la afirmación de que «no hay hechos sino interpretaciones» - tendrá, a su juicio, consecuencias normativas. Pues si entendemos la historia moderna como «la historia progresiva de disolución, en múltiples niveles, de todas las estructuras fuertes», ${ }^{1}$ es decir, de todos los hechos dados por anticipado como tales, y a dicha historia de disolución como una consecuencia resultante en gran medida del desarrollo de la tecnociencia, entenderemos también que, ubicados como estamos en esa historia, nos resultaría inaceptable cualquier posición que se fundara en la pretensión de «imponer» hechos de cualquier tipo (por ejemplo: que el hombre sea 'ángel caído' o 'mono desnudo') es decir, de proporcionar enunciados con carácter absoluto, pleno, no susceptibles de ser criticados (Vattimo 1999: 82-83). Lo que, en cambio, podría resultarnos aceptable son aquellas posiciones susceptibles al efecto de mediación interpretativa de los demás, abiertas a la crítica y al consenso, entendido este como punto de encuentro posible y a menudo provisional entre interpretaciones diversas.

Es en este efecto normativo, derivado de la disolución progresiva de los hechos, en el que se esconde, desde el principio, el poder salvador de la tecnociencia. De acuerdo con Vattimo, este poder toma la forma de un ideal: el ideal de reducción de la violencia. «Es con esta lucha entre interpretaciones con que la Edad Moderna se introduce en la fase más decisiva y, presumiblemente, más duradera de toda su historia», escribe Heidegger (1998: 77). Una fase en la que, para decirlo con él mismo, «se abre el espacio en el que se decidirá si el ser volverá a ser capaz de un dios o si la esencia de la verdad del ser exigirá la esencia del hombre de una manera más originaria» (1998: 90).

\subsection{Tecnologías emergentes y subversión}

Determinar el potencial subversivo, contrahegemónico, emancipador, de las tecnologías emergentes ha sido la tarea de pensadores indistintos a ambos lados del Atlántico. Para efectos de este trabajo me contentaré con citar dos de las fuentes más significativas: G. Deleuze y F. Guattari, en Francia, y Donna Haraway, en los Estados Unidos.

Deleuze y Guattari piensan que las tecnologías electrónicas que promueven la interactividad, la multiplicidad de trayectos (piénsese en lo

1 Evidencias de este proceso de disolución son, según Vattimo, «la secularización de la tradición religiosa, secularización del poder político, disolución de las ultimidades incluso en el seno del sujeto, fragmentación de toda racionalidad central con la multiplicación de las ciencias especiales y su tendente irreductibilidad a un esquema unitario; pluralización de los universos culturales contra la idea de un decurso unitario de la historia humana» (1999: 82). 
idiosincrásico que puede ser navegar en internet), la procesualidad singular, etcétera, subvierten muchas de las premisas educativas dominantes, premisas que, en el espacio de ciertos imaginarios sobre el desarrollo, «demandan pasividad, homogeneidad y énfasis, no en los procesos, sino en los estados a ser alcanzados» (Escobar 1999: 349). Piensan estos autores que el mundo inaugurado por estas nuevas tecnologías es «rizomático»y «multidireccional» y, por lo tanto, subversivo, en la medida en que compite con los esquemas dominantes lineales, «arborescentes», predecibles (1999: 349). Consideran así que ellas enriquecen las formas de alteridad al ofrecer espacios alternativos a las formas de relación social que se establecen según los dictados de la razón estratégica: «En los mundos concebibles desde las nuevas realizaciones tecnológicas solo abusivamente podremos colocar los determinantes económicos en una posición de primacía sobre las relaciones sociales y la producción de subjetividad», nos dice Guattari (citado en Escobar 1999: 349). ${ }^{2}$

En una línea similar, Donna Haraway ha retomado la imagen del hipertexto y ha descifrado en ella un principio políticamente útil: la conectividad. «Quiero alentar a las feministas a participar más estrechamente de los procesos de creación de significado [...] Así mismo, la figura del hipertexto debe incitar nuestro anhelo por mundos apenas imaginables, más allá de la lógica explícita de cualquier Red», dice la autora (citada en Escobar 1999: 380). ${ }^{3}$ Haraway piensa que las tecnologías digitales pueden ser situadas con utilidad en el espacio de grupos específicos que pueden extraer de ellas «regímenes de libertad» (piénsese en el efecto catalizador sobre la creatividad de grupos activistas de derechos humanos o de protección ambiental que ofrecen estas tecnologías). Su interés apunta a ubicar los potenciales de las nuevas tecnologías digitales en orden a optimizar los regímenes de apropiación de conocimientos, de prácticas y de poder por parte de grupos subalternos establecidos en contextos determinados, es decir, «posicionados». Es precisamente en el eje interactividad y posicionalidad en que Haraway ubica la función política de estas tecnologías y su promesa democrática.

Ambas posiciones, la de Deleuze y Guattari, y la de Haraway, coinciden, como puede reconocerse, en atribuir un potencial innovador y contracultural a las nuevas tecnologías. Ambas contribuyen a disolver, al menos en parte, la imagen siniestra de una tecnología ubicada del lado del poder y orientada según intereses de clase. Juntas convienen en reconocer en ellas un equipaje de utopía, o mejor, de heterotopías, es decir, de múltiples esperanzas de transformación de aquellos órdenes hegemónicos que con

2 Para una ampliación véase Guattari (1996).

3 Para una ampliación véase Haraway (1997). 
injusticia condenan al individuo al aplanamiento de su identidad y a tantos grupos a la subalternidad.

\section{No violencia y deber de cuidado}

En las dos secciones anteriores he avanzado en identificar las razones que nos permiten hablar de tecnociencia, y en caracterizar lo que he llamado, con Hölderlein, su potencial salvador. Tal potencial, he argumentado, se hace reconocible, en primer lugar, cuando decidimos «escuchar las transformaciones que la tecnociencia, como factor decisivo de la modernidad, aporta al sentido del ser», extrayendo de ello consecuencias normativas -el ideal de reducción de la violencia- $-\mathrm{y}$, en segundo, cuando nos ponemos a la tarea de hacer evidentes los potenciales contrahegémonicos que se esconden en las nuevas tecnologías emergentes. Me resta explicar el modo en que el ideal de reducción de la violencia debe comprenderse.

Como vimos, el ideal de reducción de la violencia implica apertura a la crítica, vocación de consenso y aceptación del nihilismo (esto es, del mundo como lugar de interpretaciones) como hilo conductor para «juicios, orientaciones de la vida individual y colectiva». Si, por virtud del nihilismo de nuestra época (cuya fuente principal ha sido la tecnociencia) hemos desnaturalizado la naturaleza y convenido en que ella no es más «realidad ahí afuera» sino "producción interpretativa», entonces hemos de aceptar que cualquier «diálogo» que establezcamos con ella, que esté orientado a su salvaguarda, será en cierta forma ficticio y experimental. Quisiera insistir, en todo caso, en que dicho diálogo es necesario para evitar imponer a otros, presentes y futuros, una interpretación del mundo que pueda sacrificar sus posibilidades de existir, al igual que todos, interpretativamente. Es por ello que se hace necesario el cuidado de las condiciones (de habitabilidad del mundo) en que este diálogo pueda ser posible.

El cuidado, escribe Heller, implica un deber moral real y otro hipotético (1995: 86). Como Vattimo, ella piensa que el cuidado del mundo se justifica en el ideal de reducción de la violencia hacia todo otro en el presente y el futuro. Este ideal nos exige responder ante los interlocutores potenciales frente a los reclamos que ellos pudieran hacernos por hacer el mundo inhabitable. He ahí el deber moral real. Pero Heller introduce además la idea de que tenemos un deber hipotético. El deber hipotético resulta de un examen de lo que el cuidado en verdad implica: «no es solo el mundo exterior lo que ha de protegerse sino el Cuerpo de la naturaleza, un organismo vivo. Pues, ¿cómo podría cuidar uno un 'universo de materia muerta', un universo puramente exterior?» (Heller 1995: 85-86). Por consiguiente, según ella, «resurrección de los muertos 
sería equivalente a responsabilidad hipotética» (1995: 85-86). ${ }^{4}$ Tenemos pues ambos deberes. El deber de cuidar el mundo para los que vendrán y el deber de imaginarlo vivo, sensible, orgánico, cargado de subjetividad, «como si fuese parte de nosotros»; solo así el cuidado podrá ser real.

¿Cómo pueden naturaleza y Otros llegar a formar parte de lo que somos? ¿Qué exige de nosotros la responsabilidad hipotética? Gregory Bateson ha ofrecido pautas para entender su contenido y alcance. Según él, dicha responsabilidad parece exigir pautas que [nos] conecten [a ella; a ellos]. Esas pautas están representadas, según su punto de vista, por el pensamiento creatural, un pensamiento que, como quisiera mostrar, coincide con el pensamiento que, según Lévinas, se abre al infinito. Exploraré, en lo que sigue, el modo de pensar que constituye este pensar-que-conecta.

El contraste que hace Bateson entre pensamiento del pleroma (pensamiento que elabora descripciones científicas) y pensamiento creatural, puede equipararse con el contraste que hace Lévinas entre totalidad e infinito. El saber, en Lévinas, o el discurso de la ciencia, en Bateson, están orientados a la descripción de realidades materiales, a aquello que el propio Lévinas llama un orden finito. Los enunciados del saber, de la ciencia, se dirigen a lo que Heidegger llamó «un sector de objetos» constante. Como tal, este sector de objetos conforma un reino finito, un reino en el que el mundo aparece siempre el mismo. En un reino como este la sensación de empatía creatural, de afinidad subjetiva entre la criatura que observa y el mundo de criaturas que se percibe vivo - la naturaleza- desaparece: la naturaleza es desencantada; le es arrancada su alma.

En contraste con el pensamiento del saber, el pensamiento creatural o el pensamiento que piensa el infinito no se refiere jamás a cosas, a ningún reino de objetos, precisamente. Según Bateson, el pensamiento creatural llega a definirse como tal a través de un «curioso lenguaje que no contiene cosas [sino] que solo contiene diferencias y relaciones» (Bateson \& Bateson 1994: 189). El pensamiento creatural se da en el Arte, el Mito y las relaciones interpersonales: «Los sectores de comunicación que más se aproximan a la Creatura, aun en forma lingüística, parecen darse en la religión y en las artes, en las relaciones interpersonales y en el proceso primario en general: sueños, visiones, imaginaciones» (1994: 189). Sin estos «sectores de comunicación» el pensamiento incurre en errores epistémicos; falla, por así decirlo, en su papel de intérprete del mundo-a-ser-cuidado: sin él, escribe Bateson, «no solo interpretamos mal y maltratamos los prados, los océanos y los organismos de todas clases, sino que nos maltratamos los unos a los otros basándonos

4 La distinción que elabora Heller entre «universo exterior» y «cuerpo de la naturaleza» surge de la lectura que hace del primer capítulo del texto de Jonas (2000). 
en errores de orden general de ignorar aquello con lo que estamos tratando o de obrar de maneras que violan la red comunicativa» (1994: 189). El pensamiento artístico o mítico que no contiene cosas sino ya meramente diferencias y relaciones es un pensamiento orgánico, un pensamiento que no se resuelve como saber de un mundo exterior, sino como experiencia de integración en un cuerpo vivo - la naturaleza - irreductible al saber de las cosas. En tal sentido, el pensamiento creatural es un pensamiento que conecta: al pensar como lo hace resucita, como dice Heller, el carácter vivo, sensible, cargado de subjetividad, de la naturaleza.

También en Lévinas el pensamiento que piensa lo infinito es ese pensamiento que «interrumpe la serie» de los entes, la serie finita de todo aquello que se puede resolver como saber. El otro es, por contraste con lo otro, esa «alteridad inasimilable [...] en relación con todo lo que se muestra, se señala, se simboliza, se anuncia y se rememora», es decir, en relación con todo lo que se sabe (Lévinas 1993: 75). El rostro del otro impone a quien lo encara su propio sí, su propia «unidad excepcional». En el momento en que el rostro del otro impone a cada uno la conciencia de sí, elimina la posibilidad de que cada uno pueda tomar distancia de sí mismo, es decir, elimina la posibilidad de que cada uno pueda verse a sí mismo como un individuo dentro de la serie de lo finito, dentro del reino de las cosas. Al impedir que esto pueda suceder es que el rostro del otro abre al pensamiento lo infinito. El infinito es ese pensamiento que piensa más de lo que piensa: en el cara a cara el pensamiento piensa al otro y, a su vez, a sí mismo, de un modo no epistémico, de un modo no objetivo, de un modo inmediato que no tiene relación ninguna con el tomar distancia de las cosas, es decir, con el saber. La conciencia de sí de un sujeto remite así, siempre, al rostro del otro. Esta conciencia es en sí misma irrenunciable, no exige que se establezca ningún compromiso de nuestra parte (1993: 245 y ss). De ahí que Lévinas diga que somos rehenes del rostro del Otro y que es el rostro del Otro el que nos salva.

Tanto el Arte o Mito como el rostro del otro quebrantan la economía de lo real que el saber establece. Al quebrantarla de este modo, arte y mito, y rostro del otro, nos permiten pensar pensamientos que conectan. Si es la ecología la ciencia que se ha orientado a explorar las pautas que conectan la vida de unos seres con la de otros en un ambiente determinado, es la ecología de la mente la fórmula con la cual Bateson sintetiza el conjunto infinito de pautas que conectan la conciencia con el reino de lo vivo y con el reino de lo infinito - que incluye al rostro del otro y a la naturaleza-. Solo mediante estas pautas podremos responder a las demandas que nos impone la, llamada por Heller, responsabilidad hipotética hacia el mundo que habitamos. 


\section{Referencias}

BAteson, G., \& BAteson, M.C. (1994). El temor de los ángeles. Barcelona: Gedisa.

Escobar, A. (1999). El final del Salvaje: naturaleza, cultura y política en la antropología contemporánea. Bogotá D.C.: ICAN-CEREC.

GuAttari, F. (1996). Caosmosis. Un nuevo paradigma estético. Buenos Aires: Manantial.

HARAWAY, D. (1997). Modest_Witness@Second_Millenium. FemaleMan_Meets_ OncoMouse $^{T M}$. New York: Routledge.

HeIDEgGer, M. (1993). Ciencia y técnica. Santiago de Chile: Universitaria.

Heidegger, M. (1998). Caminos de Bosque. Madrid: Alianza Editorial.

Heller, A. (1995). Biopolítica. La modernidad y la liberación del cuerpo. Barcelona: Península.

Jonas, H. (2000). Principio vida: hacia una biología filosófica. Madrid: Trotta.

LÉVINAS, E. (1993). Entre nosotros. Ensayos para pensar en otro. Valencia: Pretextos.

RorTy, R. (1991). Contingencia, ironía y solidaridad. Barcelona: Paidós.

VATtimo, G. (1995). Más allá de la interpretación. Barcelona: Paidós.

Vattimo, G. (1999). Hermenéutica, Democracia y Emancipación. Leviatán: Revista de hechos e ideas, (63): 75-86. ISSN 0210-6337. 